\title{
SAFETY OF THE REAR SEAT PASSENGER: THE IMPORTANCE OF A NEW LEGISLATION
}

Sivasubramaniam M. ${ }^{1}$, Sarathchandra Kodikara. ${ }^{2}$, Jayasooriya R.P. ${ }^{1}$, Chandrakirthi A'

${ }^{1}$ Office of the Judicial Medical Officer, Teaching Hospital, Kandy, ${ }^{2}$ Department of Forensic Medicine, Faculty of Medicine, University of Peradeniya, Sri Lanka

\begin{abstract}
The enforcement of law for the front seat occupants to wear seat belts and timely deployment of air bags during crashes has unquestionably reduced front seat occupant morbidity and fatality. However, law does not impose any regulation for the rear seat passengers to wear seat belts in Sri Lanka. As a result an increased incidence of rear seat passenger fatality in high speed crashes is observed in forensic practice. This communication presents four unrestrained rear seat passenger fatalities, in two similar crashes. Imposing of regulations in Sri Lanka to wear seatbelts for rear passengers is strongly recommended as it minimizes fatalities/injuries, not only in rear seat passengers but in all the occupants of a vehicle.
\end{abstract}

Key words: Rear seat passenger, road safety

Corresponding author: kaskodikara@yahoo.com

\section{INTRODUCTION}

The enforcement of law ${ }^{1}$ for the front seat occupants to wear seat belts and timely deployment of air bags during crashes has unquestionably reduced front seat occupant morbidity and fatality. However, law does not impose any regulation for the rear seat passengers to wear seat belts in Sri Lanka ${ }^{1}$. Rear seat passengers make use of this legal silence and tend, not to wear seat belts. However, an increased incidence of rear seat passenger fatality in high speed crashes is observed in forensic practice even in supposedly "safe modern car", when the same vehicles' front seat passengers escape injury ${ }^{2}$. Restraint of rear seat passenger with seat belt is considered an effective means of reducing injuries to the rear seat passenger as well as reduction of injuries to front seat occupants ${ }^{2}$. This communication presents four unrestrained rear seat passenger fatalities, in two similar crashes highlighting the importance of imposing law for the rear seat passengers to wear seat belts in order to prevent such fatalities.

\section{Case 1}

Four vehicle occupants returning home to Kandy from Kegalle, past mid-night were admitted to the hospital following a collision of their modern car with a water bowser from behind at Peradeniya. The driver, on examination had some chest pain on deep breathing and was discharged the same day. He had no memory of the accident and claimed that he was aware about the timely deployment of air bags. The front seat passenger was discharged the following day with only some discomfort in his chest. Both of them showed negative results for the clinical examination for the drunkenness.

Both rear seat occupants were dead on admission, one with a large scalp laceration and a hinge fracture of the skull and the other with a flail chest and cardiopulmonary contusion detected at autopsy. None of the deceased persons had blood alcohol. 
The examination of the scene revealed no tire marks to suggest any breaking. Gross damage on car's front crumple zone (Figure 1) suggested a high speed when it was collided the water bowser.

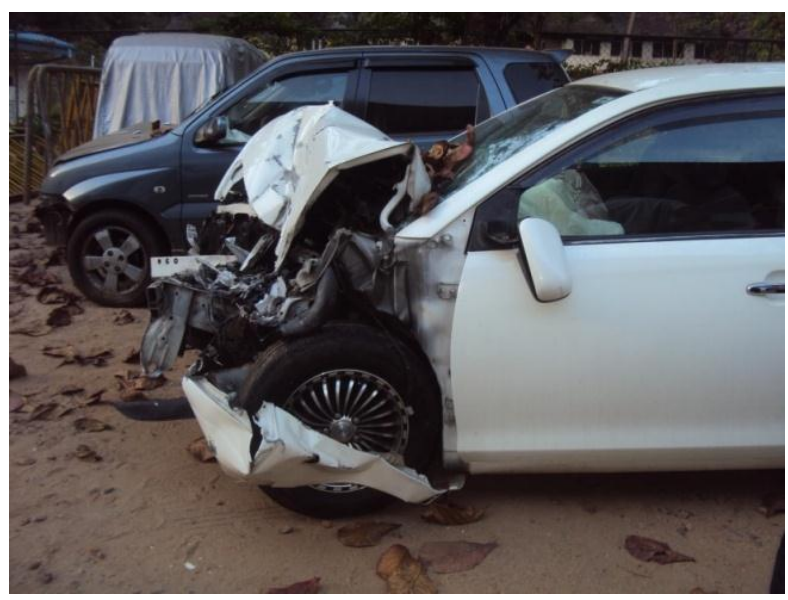

Figure 1: Extensive crumple zone damage and deployed air bags

\section{Case 2}

A family returning after visiting their relatives in Mathara in their modern car collided with a bus from behind in Kegalle close to mid-night. The driver, who was the elder son and father, who was the front seat passenger, wore seat belts and survived with no injuries. The two unrestrained rear seat passengers, mother and younger son suffered head and cervical spine injuries and succumbed to the injuries shortly on admission. None had blood alcohol. Scene examination revealed extensive collapse of the frontal crumple zone of the car (Figure 2).

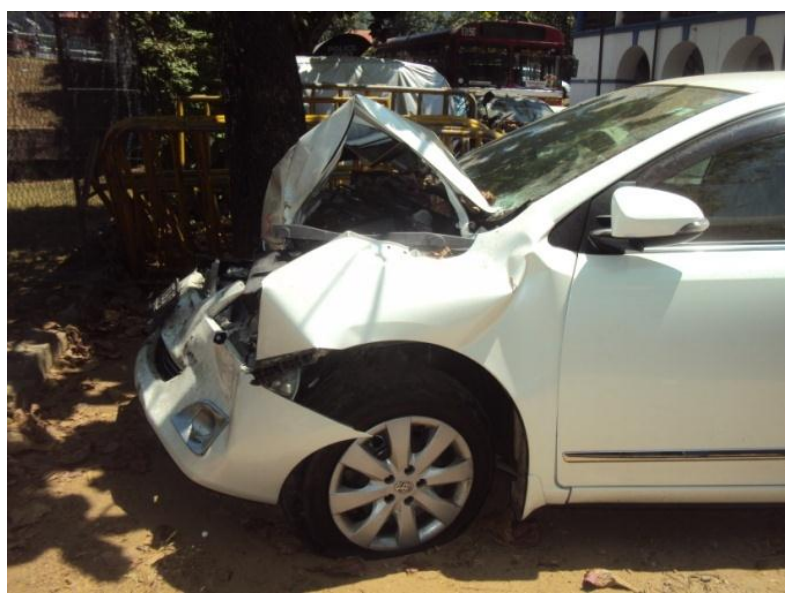

\section{DISCUSSION}

When struck against another, the motion of vehicles and occupants are left to the laws of physics of momentum and inertia. In both case scenarios the rear seat passengers who were unrestrained, possibly hurled inside the vehicles dashing against seats, tempered glass and hard/sharp objects carried inside passenger compartment. In a research done in Japan, the unbelted rear seat dummies were thrown around inside the passenger compartment, making contact at several locations such as thrown over the front seat, making contact with the front seat, roof and instrument panel $^{3}$. This study demonstrated that a rear seatbelt is useful for preventing hard contact with the vehicle interior ${ }^{3}$. Restrained rear seat passenger does not only prevent serious injuries/fatalities against $\mathrm{him} / \mathrm{her}$ but, those against front seat passenger/driver too ${ }^{2}$.

Wearing of rear seat belts has been made compulsory by law in Australia, Czech Republic, Finland, France, Germany and many other countries ${ }^{4}$ thought it has not been made compulsory in India, Indonesia, and Philippines including Sri Lanka ${ }^{4}$. The availability of highways, modern fast cars with up-to date safety features could not counter the negligence of not wearing the readily available rear passenger seat belt. The situation worsens when it is associated with fatigue of long distance travel that falters driver reflexes and even causing the driver to fall asleep as it appears clearly to be the case in $1^{\text {st }}$ case scenario described above.

\section{CONCLUSION}

Imposing of regulations in Sri Lanka to wear seatbelts for rear passengers is strongly recommended as it minimizes fatalities/ injuries, not only in rear seat passengers but in all the occupants of a vehicle.

Figure 2: Extensively collapsed crumple zone. 


\section{REFERENCES}

1. Regulations made by the Minister of Transport under section 19 and 157A read with section 237 of the Motor Traffic Act, (Chapter 203), The Gazette of the Democratic Socialist Republic of Sri Lanka. 1718/12, 2011-05-09.

2. Shimamura M, Yamazaki M, Fujita G. Method to evaluate the effect of safety belt use by rear seat passengers on the injury severity of front seat occupants. Accid Anal Prev. 2005 Jan; 37(1):5-17.

3. Mizuno K, Ikari T, Tomita K, Matsui Y. Effectiveness of seatbelt for rear seat occupants in frontal crashes. http://wwwnrd.nhtsa.dot.gov/pdf/esv/esv20/07-0224O.pdf, accessed on 20-10-2016.

4. https://en.wikipedia.org/wiki/Seat_belt_legisl ation accessed on 20-10-2016 